\title{
EL OBISPADO DE BURGOS EN LA BAJA EDAD MEDIA. FORMAS DE FORTALECER SU JURISDICCIÓN FRENTE AL MONASTERIO DE SAN SALVADOR DE OÑA ${ }^{1}$
}

\author{
THE BISHOPRIC OF BURGOS IN THE LATE MIDDLE AGES. \\ WAYS OF STRENGTHENING ITS JURISDICTION \\ AGAINST THE MONASTERY OF SAN SALVADOR DE OÑA
}

CARMEN DíEZ HERRERA Universidad de Cantabria

Resumen: Se consideran los diferentes procedimientos que desarrolló el obispado de Burgos en la Baja Edad Media para intentar implantar su jurisdicción en las iglesias de su diócesis frente a las competencias desempeñadas por monasterios como San Salvador de Oña en sus iglesias y monasterios dependientes. Un pleito establecido entre la abadía de San Salvador de Oña y los clérigos de la iglesia de Santa Eulalia de Liencres (Cantabria) sirve para poner de relieve alguno de esos procedimientos utilizados por el obispado de Burgos para intentar imponer su autoridad en una iglesia monasterial parroquial al favorecer, a petición de los hijos de la villa, su transformación en iglesia parroquial difusa. Este artículo ayuda a definir el concepto de iglesia difusa a la vez que revela el conflictivo camino que tuvo que recorrer la institución episcopal hasta conseguir el reconocimiento efectivo de sus derechos.

Palabras clave: San Salvador de Oña; Santa Eulalia de Liencres; iglesia difusa; obispado de Burgos; organización episcopal; conflicto jurisdiccional; iglesia parroquial.

\begin{abstract}
The bishopric of Burgos employed different procedures in the late Middle Ages in an attempt to impose its jurisdiction on the churches of its diocese and against the power that monasteries like San Salvador de Oña held over their dependent churches and monasteries. A lawsuit between the abbey of San Salvador de Oña and the priests of Santa Eulalia in Liencres (Cantabria) is described to highlight some of the procedures used by the bishopric of Burgos to try to impose its authority over a monastic parish church, by favouring, at the villagers' request, its transformation into a difusa parish church. This paper helps to define the concept of a difusa church, whilst demonstrating the difficult path the episcopal institution had to take in order to achieve the effective recognition of its rights.
\end{abstract}

Keywords: San Salvador de Oña; Santa Eulalia de Liencres; difusa church; bishopric of Burgos; episcopal organization; jurisdictional conflict; parish church.

${ }^{1}$ Este trabajo se ha realizado en el contexto del proyecto de Investigación HARD 201341179-P (Ministerio de Economía y Competitividad) que lleva por título Cultura, poder y redes sociales en la Castilla Medieval: el clero diocesano y catedralicio en la Baja Edad Media, dirigido por la doctora Susana Guijarro González del Departamento de Ciencias Históricas de la Universidad de Cantabria. 


\section{SUMARIO:}

1. Introducción. Objetivo e hipótesis del trabajo.- 2. La rivalidad institucional entre San Salvador de Oña y el obispado de Burgos.- 2.1. Antecedentes.- 2.2. Las disputas con San Salvador de Oña.- 2.3. Otras formas de enfrentamiento por los derechos parroquiales.- 2.3.1. El caso de Santa Eulalia de Liencres: el intento de transformación de una iglesia monasterial parroquial dependiente de San Salvador de Oña en una iglesia parroquial difusa de hijos de villa.- 2.3.1.1. La iglesia de Santa Eulalia.2.3.1.2. Los protagonistas implicados en el enfrentamiento.- 2.3.1.3. La reconstrucción de los hechos y el desenlace final.- 3. Conclusiones.- 4. Bibliografía citada.

\section{INTRODUCCIÓN. OBJETIVO E HIPÓTESIS DEL TRABAJO}

El proceso de construcción territorial de las diócesis, el desarrollo del poder episcopal y el encuadramiento eclesiástico constituyeron en la Edad Media fenómenos muy complejos, largos y en constante evolución ${ }^{2}$. La configuración definitiva de los espacios adscritos a cada sede episcopal, la definición de la geografía parroquial y, sobre todo, el ejercicio pleno de los derechos episcopales reconocidos por las leyes canónicas se llevó a cabo de forma progresiva y muy controvertida, pues aunque la legislación canónica reconocía el ius episcopale en todas las iglesias comprendidas en el territorio diocesano, los derechos alegados por otras entidades como iglesias y monasterios propios o por señoríos monásticos sólidamente asentados en el territorio de la diócesis dificultaron el desarrollo de una red parroquial operativa y el ejercicio efectivo de las competencias de los prelados ${ }^{3}$.

En efecto, los distintos regímenes de titularidad y patronazgo de las iglesias de la diócesis y las exenciones de jurisdicción de algunas entidades complicaba el desempeño de las funciones propias de las sedes episcopales. El proceso de transformación de muchas pequeñas iglesias rurales en templos parroquiales dependientes del Obispado fue gradual y no exento de enconados enfrentamientos con los titulares de las iglesias, ya fueren estos instituciones monásticas, señores laicos o comunidades de campesinos. Este complejo proceso, poco conocido en general ${ }^{4}$, generó diversos tipos de conflicto entre las distintas entidades que competían en el territorio diocesano.

\footnotetext{
${ }^{2}$ Calleja 2000.

${ }^{3}$ López 2002, p. 432. Como afirma este investigador en un plano teórico, la disciplina canónica de la iglesia hispánica preveía el control episcopal de todas las iglesias comprendidas dentro de un Obispado.

${ }^{4}$ Es común entre los historiadores la llamada de atención sobre la carencia de trabajos sobre este tema. María José Lop habla de una cierta "debilidad" historiográfica de los estudios parroquiales. Lop 2009, p. 256; véase también Peñalva 2008.
} 
El objetivo de este trabajo ha sido el análisis de alguna de las formas mediante las cuales el obispado de Burgos intentó fortalecer su jurisdicción y el desarrollo de sus derechos en las iglesias de su diócesis en la Baja Edad Media frente a las competencias desempeñadas por grandes monasterios, en este caso, el de San Salvador de Oña. En primer lugar se ha procedido a conocer los motivos, las etapas de los enfrentamientos más directos entre ambas instituciones por medio del análisis de los pleitos y reclamaciones seculares ante la Santa Sede, y en segundo lugar se ha procedido al análisis de otras intervenciones episcopales más encubiertas y sutiles con similares objetivos y resultados menos garantizados.

Respecto a las fuentes utilizadas, existe una documentación muy valiosa para el fin pretendido que procede de la catedral de Burgos y especialmente del fondo documental de la abadía de Oña ${ }^{5}$. De ella es conveniente señalar algunos aspectos de interés; el primero de ellos que de la información procedente de Oña debe destacarse por su elevada significación para este estudio la conservada sobre un complejo contencioso desarrollado en el siglo XIV entre el monasterio de Oña y varios clérigos de Liencres. La información más interesante para nuestro objetivo está contenida en las casi cien páginas, según la edición de Oceja, de las respuestas que durante dos meses dieron setenta y nueve testigos de las partes litigantes ${ }^{6}$. A pesar de la parcialidad de los encuestados, (es evidente que cada uno de ellos proporcionó "su" versión), y de las diferencias entre las cuestiones planteadas a los testigos de cada uno de los contendientes ${ }^{7}$, se ha podido extraer una información muy útil para el objeto de estudio de este trabajo en tanto que ha podido ser contrastada con otros documentos del mismo fondo. El segundo aspecto de interés se refiere a que no deja de sorprender que en la documentación procedente de Burgos no exista ni una sola alusión al conflicto mencionado generado en el siglo XIV sobre la iglesia de Santa Eulalia.

Como hipótesis de trabajo se parte de la consideración de que el obispado de Burgos, a la vez que utilizaba los procedimientos habituales de reclamación de sus derechos ante la Santa Sede frente a las competencias desempeñadas por instituciones monásticas que limitaban su poder (en el caso estudiado el monasterio de Oña), intentó activar otras vías para ampliar la efectividad de su jurisdicción y conseguir la exacción de sus derechos parro-

${ }^{5}$ Editada por Álamo 1950 y Oceja 1983, 1986a, 1986b, 1986c. En adelante citados: Álamo $1950, n^{\circ}$ doc. Y Oceja 1983, 1986a, 1986b y 1986c, no doc.

${ }^{6}$ Treinta y nueve testigos del abad y del monasterio de Oña, uno de ellos el último arrendatario conocido de Santa Eulalia. Oceja 1986c, n 601, pp. 119, 120, 132, 133.

${ }^{7}$ Les interesaba sobre todo lo referente a los derechos del Obispo y a conocer en virtud de cómo y por qué cantaban los clérigos la iglesia, si lo hacían por soldada o mediante retribución en la participación de las rentas eclesiásticas. 
quiales en el ámbito de su diócesis. El Obispado, para conseguir sus objetivos, no dudó en facilitar la transformación del régimen de algunas iglesias, monasteriales parroquiales o con otras categorías, atribuyendo o reconociéndoles un antiguo carácter difuso o comunitario, ni tampoco en favorecer el abandono del culto de iglesias monasteriales parroquiales y en colaborar en la promoción y reconocimiento de otras iglesias o ermitas locales como nuevos centros parroquiales, generalmente también, atribuyéndoles un carácter de iglesia parroquial difusa. Para ello contó con un aliado circunstancial inestimable; las propias comunidades a través de sus concejos en un contexto, generalizado desde el siglo XIII, de un creciente interés colectivo, como ha puesto de manifiesto Isabel Alfonso, en apropiarse y/o controlar los cada vez más interesantes recursos de las iglesias parroquiales locales ${ }^{8}$.

Como puede observarse, en cualquiera de estos procesos el régimen de iglesia difusa alcanzó una singular importancia; beneficiaba a los parroquianos en tanto que les reconocía la titularidad, la administración del centro de culto local y la participación en sus rentas, y al señor Obispo en tanto que podía suponer para el Obispado una vía de incorporación de iglesias monasteriales parroquiales en la nómina de las parroquias de la Sede o de creación de nuevas parroquias bajo su control. Y, sobre todo, le permitía acceder a las rentas eclesiásticas que le correspondían y que, por la inmunidad o la resistencia de algunos monasterios como Oña, aún no percibía.

Antes del desarrollo del tema es conveniente recordar algunas consideraciones sobre las diferentes categorías de iglesias en el obispado de Burgos en el siglo XIV, y sobre el concepto de iglesia difusa. Serrano proponía una clasificación de las iglesias de la diócesis de Burgos en cuatro categorías: las propias de la dignidad episcopal; las libres, parroquias y ermitas, cuya propiedad no pertenecía al Obispo y dependían directamente del prelado; las de patronato laical; y las de cabildos, colegiatas y órdenes religiosas ${ }^{9}$. En la documentación consultada en esta ocasión aparecen en el siglo XIV al menos dos de ellas. Unas, las iglesias de órdenes religiosas como Oña, las iglesias monasteriales parroquiales; en ellas, según describe un documento conservado en Oña de 1295, era donde se

oyeren e deven oyr las oras e dezmar e premiçiar e facer todas aquellas cosas que cristianos deven facer a la iglesia dont son parrochianos e deven reçebir todos los sacramentos de la eglesia ${ }^{10}$.

\footnotetext{
${ }^{8}$ Alfonso 2010.

${ }^{9}$ Serrano 1935, vol. II, pp. 204-207.

${ }^{10}$ Oceja 1986a, $n^{\circ} 378$.
} 
Es decir, las que ejercían como parroquiales pero vinculadas a dominios monásticos con exención apostólica, aunque el Obispo correspondiente se resistiese y reclamase sus derechos. De hecho se recuerda que: no posint monachi, pleno iure, parrochiales ecclesias posidere nec plebis curam suscipere aut etiam excercere ${ }^{11}$. Y otras, las libres, entre ellas las iglesias difusas parroquiales es decir: la que diezman e primiçian a los que la cantan, que son fiios de vecinos ${ }^{12}$. Eran las patrimoniales, en las que el nombramiento de sus curas y clérigos debía recaer forzosamente en hijos de la parroquia, y donde el Obispo gozaba de todos los derechos diocesanos ${ }^{13}$. Y también las ermitas sin funciones de cura de almas, es decir sin pila, sin sacramentos y por ello sin feligreses ${ }^{14}$.

Dado el interés que para el tema de este trabajo tuvieron las iglesias difusas es conveniente indicar alguna de sus características. ¿Qué se entiende por parroquia difusa en la Edad Media? En principio se puede afirmar que constituye un régimen de iglesia vigente pero no exclusivamente en la diócesis de Burgos cuyos orígenes pueden estar relacionados con tradiciones comunales de iglesias comunitarias indivisas que tuvieron una difusión por el área norpeninsular castellana. Con la denominación de iglesia difusa se la conoce básicamente en la sede burgalesa ${ }^{15}$ aunque también se utilizó la misma expresión en alguna ocasión en la documentación de los obispados de Astorga, de León y de Palencia ${ }^{16}$. Sin embargo, el concepto que implica el término difusa como iglesia patrimonial en la que las comunidades detentaban la propiedad, elegían a sus clérigos entre los vecinos del lugar y recibían participación en el reparto decimal, es posible también relacionarlo con estructuras parroquiales existentes en otros territorios, con iglesias concejiles en Tierra de Campos, en Pamplona, en Calahorra ${ }^{17}$. Con lo que la extensión territorial de este tipo de régimen de iglesia debió de ser bastante superior a la que se puede deducir atendiendo exclusivamente a las menciones que llevan el calificativo difusa. El Becerro de las Presentaciones de la diócesis de León acredita que perduró por siglos en gran número de lugares, desde las montañas cantábricas a los montes Torozos ${ }^{18}$.

${ }^{11}$ Oceja $1986 \mathrm{c}, \mathrm{n}^{\mathrm{o}} 617, \mathrm{p} .178$.

${ }^{12}$ Ibidem, $\mathrm{n}^{\mathrm{O}} 601, \mathrm{p} .114$.

${ }^{13}$ Serrano 1935, vol. II, p. 205.

${ }^{14}$ Oceja $1986 \mathrm{c}, \mathrm{n}^{\circ} 601, \mathrm{p} .95$.

${ }^{15}$ El concejo de Gamonal dice en 1328 que la iglesia de Santa María de Gamonal era suya y difusa, "según la costumbre general en la diócesis de Burgos". Archivo Catedral de Burgos, V. 29, f. 295.

${ }^{16}$ Martínez 2002, pp. 41-42; 2007, pp. 193-194.

${ }^{17}$ Alfonso 2010, pp. 51-53.

${ }^{18}$ Martínez 2007, pp. 193-194. 
En principio este régimen parece remitir a un tipo de iglesia de tradición antigua, asociada a la costumbre de la tierra. De hecho las primeras referencias se remontan al siglo X. En concreto Flórez, E., en La España Sagrada, recoge unas inscripciones de los años 991 y de 1086 en las que se alude a iglesias difusas et non divisas. La del año 1086 recuerda el acto de consagración de la iglesia de San Martín de Pieros, entre Villafranca y Cacabelos, por el obispo Osmundo de Astorga, cuyo texto de la inscripción es el siguiente: Ecce domus domini et porte celi eclesia defusa et non divisa in honore ... et edificavit Petrus presbiter ipsa eclesia Osmundo episcopus Astoricense sedis ${ }^{19}$. De lo que se deduce que la iglesia se podía crear o fundar con esa categoría, en este caso por decisión de un presbítero con la aprobación y consagración del obispo de la diócesis. Aunque es desde finales del siglo XII cuando el término iglesia difusa aparece en alguna ocasión más, especialmente en el entorno del monasterio de San Salvador de Oña. En el fuero a los collazos de la villa de Oña de 1190 se establece que la capilla de San Juan y San Martín fuese siempre diffusa omnibus tam clericis quam laicis, qui nunc habent domos et hereditates in Honia ${ }^{20}$. En este caso fue el abad de Oña el que decidió que la iglesia fuese difusa y se asocia a que debía de ser de los que acreditasen ser vecinos de Oña. En 1225 los parroquianos de Montenegro se enfrentaron a Oña afirmando que la iglesia de San Juan estaba administrada por hijos de los vecinos porque había sido diffusam ab antiquo $^{21}$. Ese mismo año fueron el concejo y clérigos de Sotovellanos los que reclamaban la misma categoría para la iglesia de San Pantaleón ${ }^{22}$. De nuevo en 1293 se utiliza esa expresión iglesia difusa de fijos de villa, con ocasión del pleito entablado por Oña contra los concejos de Berrueza y Quintanilla porque desamparaban sus iglesias parroquiales del monasterio de Oña, donde los parroquianos tenían que dar los diezmos, las primicias y las oblaciones y recibir los sacramentos de la Iglesia y oír las horas y se iban a otra iglesia que era ermita, y la hacían cantar por difusa (donde, según se puede deducir del texto, sí se podían enterrar y donde se podía disponer de parroquianos y cobrar los derechos correspondientes) ${ }^{23}$.

En la defensa que llevan a cabo unos clérigos para reclamar el carácter difuso de la iglesia de Santa Eulalia de Liencres en el siglo XIV se sinteti-

\footnotetext{
${ }^{19}$ Flórez 1737, vol. XVI, pp. 190-191.

${ }^{20}$ Martínez 1982, p. 198: doc. XXXIX, (16).

${ }^{21}$ Afirmaban que "in ista quasi posseione fuerant multi filii vicinorum qui in ista ecclesia longo tempore ministraverant". Álamo 1950, n 438. Véase al respecto Martínez 2002, p. 41.

${ }^{22}$ Álamo 1950, $\mathrm{n}^{\circ} 439$.

${ }^{23}$ Oceja 1986a, $n^{\circ} 392$. Es preciso recordar que el hecho de que se pudieran enterrar en la ermita cantada por difusa implicaba necesariamente que el Obispo lo había concedido. La ley III de la Primera Partida. Titulo XIII, así lo confirma.
} 
zan de forma clara las características de lo que podía implicar el régimen de iglesia difusa en la Baja Edad Media en la diócesis de Burgos ${ }^{24}$.

En primer lugar se puede afirmar que en el siglo XIV existía una conciencia popular generalizada de su significado: la que diezman e primician a los que la cantan que son fios de vecinos ${ }^{25}$. Difusa era la denominación común con la que se conocía este tipo de iglesia (difusa vulgariter appellate $)^{26}$. Se consideraban iglesias del concejo o de los vecinos ${ }^{27}$, comunitarias, cuyos bienes y derechos no se podían fragmentar entre los copropietarios $^{28}$ : eglesias non deviseras ${ }^{29}$. Que eran libre e quita sin embargo salvo del obispo de Burgos $^{30}$. Y requerían para su reconocimiento institucional la autorización del señor Obispo ${ }^{31}$, así como un instrumento legal de validación: la carta en como era difusa era perdida y despues parescio la carta ${ }^{32}$. Los clérigos que las atendían debían ser filios patronorum vicinorum istius loci (hijos patrimoniales) $^{33}$, y ser ordenados por el Obispo para poder ejercer en la iglesia, lo que suponía la precedencia de los naturales de la villa frente a los foráneos para ocupar los cargos eclesiásticos; cantar y llevar por suya sin premia $^{34}$. Y era la propia comunidad, el concejo, la que, con licencia del

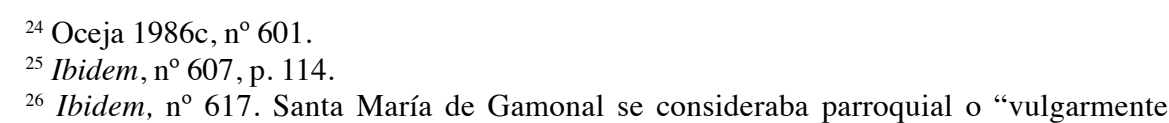
llamada difussa” tal y como afirmaban en el s. XIV los clérigos y comunidad del lugar de Gamonal.

${ }^{27}$ Como en el caso de la iglesia de Santa Eulalia de Liencres. Oceja 1986c, no 601, p. 61.

28 "clerici et laici ipsius ville diceban iam dictas ecclesias diffusas esse concilii", Abajo $1986, n^{\circ} 97$. Desde las primeras referencias conocidas de iglesias difusas el concepto aparece siempre asociado a non divisa. Cuando el conde Martín Flaínez concedió un solar a los hombres de Terradillos para edificar una iglesia con categoría de difusa insiste en que debe ser difusa et non divisa, es decir sin posibilidad de fragmentación entre los convecinos. Ruiz 1987, n $^{\circ} 1313$.

${ }^{29}$ Oceja 1986 c, no 601, p. 107.

${ }^{30}$ Ibidem, p. 86.

31 "la levaron por difusa que la avian foreada en burgos". Ibidem, p. 71.

${ }^{32}$ Ibidem, p. 106.

33 “difusa de los clérigos fijos de los parroquianos vecinos de Liencres", Ibidem, p. 65 y 67. La "propiedad" de la iglesia correspondía a los clérigos servidores de ella y a la comunidad de vecinos y parroquianos, ya que todos podían llegar a tener la condición de hijos patrimoniales y obtener un beneficio en su parroquia, tal y como se reconocerá posteriormente a las iglesias patrimoniales. Peñalva 2008, p. 310. En principio parece que en las iglesias difusas todavía no se establecía con rigor el tiempo necesario para considerar la condición de hijo patrimonial; tan solo que el clérigo fuera hijo o nieto de vecino y parroquiano. En el siglo XV ya se establece que tenían que haber sido vecinos o parroquianos por espacio de diez años. Peñalva 2008, p. 311. En Sínodos de esa época se regula la concesión de los beneficios por el Obispo a clérigos que no eran hijos patrimoniales de la iglesia de su colación, en caso de que no hubiese nadie disponible. García 1997, pp. 102-103.

${ }^{34}$ Por los "filii vicinorum qui in ista ecclesia longo tempore ministraverant". Álamo 1950, $n^{\circ} 438$. 
Obispo, tenía la capacidad de elegir a los clérigos entre los vecinos del lugar o de la villa ${ }^{35}$, que debían ser ordenados específicamente para ese lugar concreto: clerigos ordenados a titulo de liencres, por los obispos de Burgos y el arcipreste de Pagazanes ${ }^{36}$. Debían de asegurar a los clérigos los beneficios de la iglesia parroquial; ellos eran los que tenían derecho a la participación en los diezmos y primicias y se los repartían entre si ${ }^{137}$. Estas iglesias podían ser difusas parroquiales o no. La difusa parroquial tenía como función reconocida: Servir a los parrochianos e crismar e facer ley porque ayan baptismo ${ }^{38}$. Es decir la cura de almas y la administración de sacramentos ${ }^{39}$, la celebración de festividades, el control moral de la feligresía y la enseñanza de la doctri$\mathrm{na}^{40}$. Parece evidente que esta categoría de iglesia debió fomentarse desde el propio Obispado porque se atendía la iglesia, mejoraba el control de los feligreses, aseguraba a los clérigos locales los beneficios de su iglesia parroquial, y sobre todo porque, sometida al Obispado ${ }^{41}$, el prelado podía exigir los derechos episcopales: la obediencia de los clérigos que la regían y recibir la tercia decimal ${ }^{42}$.

A la vista de estas características se puede concluir que el concepto de iglesia difusa descrito puede considerarse, sin lugar a duda, el antecedente de la conocida como iglesia parroquial patrimonial no numerada caracterizada por Peñalva $\mathrm{Gil}^{43}$.

${ }^{35}$ Esa circunstancia se dio por ejemplo en Tarradillos: "clericus qui ibi fuerit missus sit in manus de vos concilio de Terratelllos" Ruiz 1987, $\mathrm{n}^{\circ} 1313$.

${ }^{36}$ Oceja 1986c, $\mathrm{n}^{\circ}$ 601, p. 80. También en la iglesia difusa de Santa María de Gamonal en Burgos los clérigos hijos de los vecinos de allí recuerdan en 1328 que deben ser ordenados e intitulados a título de dicha iglesia. Archivo catedral de Burgos, V. 29, f. 295.

${ }^{37}$ Oceja 1986c, no 601, p. 78.

${ }^{38}$ Ibidem, p. 96.

${ }^{39}$ Iglesia "don se fazian los sacramentos a los parroquianos, comulgar, velar, decir misas, crizmaban no tenia pila de batear e que los venian a batear a Santa Cruz de Bezana". A pesar de que, según parece, la iglesia de Liencres no tenía pila bautismal. Ibidem, pp. 48, 87 y 119.

${ }^{40}$ Curiel 2009, pp.101-111.

${ }^{41}$ Un testigo expresa "que en la iglesia que non es difusa que no a el obispo derecho". Oceja $1986 \mathrm{c}, \mathrm{n}^{\circ}$ 601, p. 94-95. De hecho la iglesia monasterial parroquial de Santa Eulalia de Liencres, dependiente de Oña, no satisfacía la tercia episcopal al obispo de Burgos. Los testigos del monasterio de Oña afirman una y otra vez que todavía en el siglo XIV el obispo de Burgos no tenía en la iglesia de Liencres ningún derecho. Ibidem, pp. 127 y 131.

${ }^{42}$ Cuando el concejo y clérigos de Sotovellanos llegan a un acuerdo con Oña por la iglesia difusa de San Pantaleón, se establece que el Obispo reciba su tercia. Álamo 1950, nº 439.

${ }^{43}$ Peñalva 2008. 


\section{LA RIVALIDAD INSTITUCIONAL ENTRE SAN SALVADOR DE OÑA Y EL OBISPADO DE BURGOS}

\subsection{Antecedentes}

El 18 de marzo de 1068, Sancho II de Castilla procedió a la restauración del obispado de Burgos. La nueva diócesis comprendía la casi totalidad de la actual provincia de Burgos, de la de Santander y gran parte de Vizcaya. Desde el año 1095 la diócesis de Burgos aparece exenta de todo metropolitano, definida territorialmente con la restauración de sus límites diocesanos y bajo la jurisdicción de Roma ${ }^{44}$. Sin embargo no fue hasta la Concordia de Sahagún de 1184, entre el obispo de Oviedo, que competía por alguna de estas tierras, y el obispo de Burgos, cuando las Asturias de Santillana quedaron definitivamente adscritas a la jurisdicción de la sede de Burgos ${ }^{45}$.

A partir del concilio de Coyanza en el año 1055 comenzó una lenta consolidación del poder del Obispo, con una dedicación más intensa al gobierno de su diócesis y una reafirmación de la autoridad episcopal sobre los monasterios e iglesias del territorio diocesano ${ }^{46}$. Se inició el proceso de reivindicación y reclamación de antiguas competencias episcopales en un afán de restablecer la vigencia de la legislación canónica hispano-goda: las tercias, la procuración ${ }^{47}$, los derechos de consagración (las formulaciones canónicas vigentes sentaban el principio de que la iglesia debía ser consagrada por el Obispo al menos si contaba con reliquias), los diezmos, el derecho de presentación y la ordenación de los clérigos o el derecho de catedrático.

En concreto en el obispado de Burgos se observa alguna de estas manifestaciones en tierras de Cantabria: en 1099 el obispo de Burgos consagra, a petición de los vecinos, la iglesia de San Martín de Udías, reservándose la tercia episcopal y los derechos inherentes a las visitas canónicas ${ }^{48}$. No obstante, es evidente que el Obispo ejercía en esa época su jurisdicción aún de forma precaria pues aunque el derecho episcopal establecido por las disposiciones canónicas exigía las tercias de todas las iglesias, muchas de esas iglesias en territorio de Cantabria estaban en manos de monasterios como Santa Juliana, Santa María del Puerto o de monasterios castellanos como San Salvador de Oña o Santa María de Nájera, cuyos abades eran los que de hecho percibían y retenían en su beneficio las susodichas rentas.

${ }^{44}$ Olmedo 1987, p.123.

${ }^{45}$ Peña, Álvarez 2000, pp. 109-136.

${ }^{46}$ Olmedo 1987, pp. 124, 135 y 136.

${ }^{47}$ Villacorta 2004, p. 1471, nota 30.

${ }^{48}$ Garrido 1983a, $\mathrm{n}^{\circ} 67$. 
La necesidad de controlar y recaudar los ingresos eclesiásticos generó una creciente tensión, por un lado entre las sedes episcopales por definir con mayor precisión sus respectivos límites ${ }^{49}$, y por otro frente a los señoríos monásticos por imponer o restablecer sus derechos diocesanos, sus capacidades y atribuciones ${ }^{50}$. Y así se constatan las primeras manifestaciones de la actitud reivindicativa de los Obispados para reclamar el cobro de la renta decimal de las iglesias localizadas en sus respectivas diócesis ${ }^{51}$. La cuestión de las tercias fue un tema candente desde fines del siglo XI entre las sedes episcopales y los monasterios: en el concilio de Palencia del año 1100 se decretó que los obispos no exigieran las tercias a los monasterios que probasen con sus privilegios no haberlas pagado nunca ${ }^{52}$. A pesar de ese reconocimiento la percepción de las tercias continuó siendo motivo constante de fricción entre obispos y abades. Las sedes episcopales las reclamaban, y como medida de presión se negaban a conferir las órdenes clericales a determinados monjes elegidos y presentados por los abades, en un afán por recuperar o implantar definitivamente la jurisdicción y los derechos episcopales ${ }^{53}$. Además surgieron otras cuestiones objeto de discusión entre las sedes y los monasterios, como el régimen de las iglesias, la consagración de las mismas, la ordenación de los clérigos, la imposición y cumplimiento de las penas canónicas, la distribución por las iglesias del crisma y santo óleo. Y todo ello a pesar del sucesivo reconocimiento de los derechos del prelado diocesano en iglesias y monasterios que tuvo lugar en el I (1123) y III (1179) Concilios de Letrán.

\subsection{Las disputas con San Salvador de Oña}

En ese contexto de intensa competitividad entre las sedes y los dominios monásticos, se desarrolló el secular contencioso que enfrentó a la abadía de San Salvador de Oña con el obispado de Burgos. En 1094 el monasterio de Oña se acogió a la protección pontificia, a la exención canónica, y se

${ }^{49}$ En 1088 en el concilio de Husillos y en presencia del monarca Alfonso VI se fijaron los límites de las diócesis de Burgos y Osma, delimitación que generó múltiples problemas. Puede consultarse al respecto: Ibidem, $\mathrm{n}^{\mathrm{o}} 46,47,79,86,87,88,89,90,92$.

${ }^{50}$ En 1099 desde Roma se confirmaron de nuevo los límites de la diócesis (según parece había tenido problemas con Osma) y se ordena a los nobles y a los monasterios el pago del diezmo, excepto a los que gozaban de exención apostólica. Ibidem, $\mathrm{n}^{\circ} 66$.

${ }^{51}$ Véase al respecto los trabajos de Álvarez 2004; Villacorta 2004; Pereda 1986. En el año 1087 tiene lugar la primera disputa entre el obispo de León y el abad de Sahagún.

${ }^{52}$ De hecho, las iglesias dependientes del monasterio de Sahagún no pagaban las tercias a la diócesis leonesa y tuvieron que proceder a múltiples acuerdos para conseguir que el Obispo no las demandara. Villacorta 2004, pp. 1468-1469.

${ }^{53}$ Ibidem, p. 1471. 
comprometió a pagar una onza de oro anual al palacio de Letrán ${ }^{54}$. Esto no significaba la exención de la autoridad civil y eclesiástica, es decir del pago de cualquier tributo o gravamen, pero respondía al deseo de escapar al control episcopal de las tercias, la tercera parte de todas las rentas de las parroquias. Las iglesias pertenecientes a Oña tenían que pagar las tercias al monasterio, no al obispo diocesano de cuya jurisdicción se libraban, lo que provocará graves conflictos entre el abad y el obispo desde la primera mitad del siglo XII. Según Luciano Serrano desde esa época el monasterio de Oña mantenía un duro enfrentamiento con el obispo de Burgos al reclamar éste el pago de las tercias episcopales, de diezmos y oblaciones, de las iglesias que estaban asentadas en los territorios de las diócesis, tal y como reglamentaban las prescripciones olvidadas durante mucho tiempo ${ }^{55}$. Y, según el mismo autor, éste pudo ser el móvil por el que, desde Oña, se urdió una supuesta vinculación a Cluny, ya que la sujeción directa de los monasterios cluniacenses al patronato pontificio suponía el reconocimiento de la independencia con respecto a la jerarquía episcopal ${ }^{56}$. A pesar de ello parece que la sede burgalesa no se resignaba, y en 1144 consiguió que el pontífice Lucio II ordenase a los abades de varios monasterios, entre ellos el de Oña, que abonasen al obispo de Burgos la fracción de diezmos que según los cánones le correspondían ${ }^{57}$. En el año 1150, Oña, San Pedro de Arlanza, San Pedro de Cardeña, San Millán de la Cogolla y Santo Domingo de Silos continuaban en pleito con el obispo de Burgos por razón de las tercias ${ }^{58}$, ya que las sedes episcopales exigían que para evitarlas estos monasterios tenían que probar con razones sólidas la exención apostólica de la Santa Sede. En 1152 se llegó a un principio de acuerdo refrendado por el papa entre el obispo de Burgos y San Salvador de Oña sobre la tertia parte decimarum, la primera concordia, que no debió satisfacer al Obispado pero

${ }^{54}$ El monasterio de Oña había sido recibido bajo la protección apostólica por Urbano II y Pascual II en 1094 y 1102. Álamo 1950, n ${ }^{\circ} 104,114$; Olmedo 1987, pp. 117 y 129-133. De hecho, en las cuentas de 1338, se contabiliza que daban una onza de oro por el "encenso de la Iglesia de Roma” que costaba 150 maravedíes. Oceja 1986c, no 661, p. 253. El monasterio de Sahagún, había quedado liberado de la dependencia de cualquier autoridad eclesiástica o civil que no fuera la Santa Sede desde 1083. No obstante, como muestra Villacorta, la exención del obispo diocesano respectivo se fue aclarando y ampliando progresivamente. Villacorta 2004, pp. 1460-1467.

${ }^{55}$ Serrano 1935, vol. I, p. 227.

${ }^{56}$ Faci 1977, pp. 299-317.

${ }^{57}$ Garrido 1983a, nº 129.

${ }^{58}$ Ibidem, $\mathrm{n}^{\mathrm{o}}$ 135. Antes, Lucio II había mandado al monasterio de Oña, entre otros, que pagase al obispo de Burgos los diezmos de las villas. Ibidem, $\mathrm{n}^{\circ} 129$. El papa Alejandro III comunicó al obispo de Burgos que el abad de Cardeña estaba obligado a recibirle procesionalmente y a pagarle la procuración en tanto no probase su exención por la Santa Sede. Ibidem, n 163. 
sí a Oña que buscó la confirmación posterior ${ }^{59}$. El año 1186 (poco después de la definitiva asignación a la sede de Burgos de las Asturias de Santillana, como consta en los textos conservados $)^{60}$, se reabre el proceso conflictivo con Oña y se emiten reiteradas sentencias que obligan a San Salvador de Oña una y otra vez a someterse a la jurisdicción del Obispo y a pagar los derechos episcopales $^{61}$. Los papas Urbano III, Clemente IV, Celestino III e Inocencio III insisten en el reconocimiento de los derechos episcopales de la sede burgalesa en lo referente al dictado de sentencias de excomunión e interdicto, al enjuiciamiento de causas matrimoniales, a la nominación y destitución de clérigos y a la obligación de asistencia a los sínodos, frente a la actuación rebelde y reincidente de la abadía de Oña. Sin embargo en los interrogatorios de los comisionados papales para resolver los sucesivos litigios suscitados entre ellos, varios testigos, laicos y eclesiásticos, afirmaban que nunca vieron a los obispos de Burgos recibir procuración ni diezmos ni oblaciones de las iglesias monasteriales de Oña, y que era el monasterio de San Salvador el que, por el contrario, percibía la procuración y la adjudicación de áureos, convocaba a concilio, y procedía a la institución y destitución de clérigos y a la percepción y reparto de diezmos en sus iglesias monasteriales ${ }^{62}$.

Los acuerdos, regulaciones y pleitos se prolongaron varios años. La abadía de San Salvador no se resignaba a perder sus derechos a la vez que los obispos no cesaban en sus presiones y reclamaciones ${ }^{63}$. En 1218 se llega de nuevo a otra concordia entre el abad y el convento del monasterio de Oña y el

\footnotetext{
${ }^{59}$ En 1150 se hace referencia a la controversia ente los abades de Oña y el obispo Victor sobre la tertia parte decimarum. Ibidem, $\mathrm{n}^{\circ}$ 135. En el acuerdo de 1152 el obispo de Burgos procede a conceder las tertias decimarum y el ius parrochiale que canónicamente le pertenecían, en las iglesias que el monasterio poseía en ese momento, a cambio de la cesión de la villa de Revilla. Álamo $1950, \mathrm{n}^{\circ}$ 212. Parece ser que este acto se consideró una concordia (el recuerdo de este pacto se recoge en un documento de Oña de 1209. Oceja 1983, n 107). En otro documento sobre la querella de los diezmos, datado también en torno a 1152, se dice que la concordia se había realizado sin el consenso del cabildo de Oña. Garrido 1983a, n 138. Véanse más detalles en Pereda 1986, pp. 203-208.

${ }^{60}$ En 1163 el papa Alejandro III confirma al obispo de Burgos, don Pedro, los límites, bienes y posesiones de la iglesia y diócesis de Burgos. "Totis Asturiis usque ad fluvium Deva". Garrido 1983a, n ${ }^{\circ} 165$. En 1182 es el papa Lucio III quien de nuevo confirma la posesión de todos sus bienes y derechos. Ibidem , $\mathrm{n}^{\circ}$ 219. Y en 1184 los obispos de Orense y de Palencia, delegados del papa Lucio III, ponen fin al pleito que sostenían los obispos de Oviedo y de Burgos sobre sus respectivos límites diocesanos: se admite que el monasterio de Santa María de Yermo con todas sus iglesias dependientes eran propiedad del obispo de Oviedo "salvo iure burgensis ecclesie quod antiquitus in illis habuit". Garrido $1983 \mathrm{~b}, \mathrm{n}^{\circ} 242$.

${ }^{61}$ Véase al respecto: ibidem, $\mathrm{n}^{\circ} 269,281,298,353,355,356,358,425,426,427,429,488$, 489. Se intenta regular también la visita pastoral.

${ }^{62}$ Afirmaban que cuando el obispo de Burgos "faciebat collectam in episcopatu suo", lo hacía Oña en sus iglesias: "Abbad onniensis faciebat collectas in ecclesis suis, sicut et opscopus burgensis in ecllesis suis". Oceja 1983, n 107, pp. 92 y 94.

${ }^{63}$ Aproximadamente de 1201 a 1218. Garrido 1983b, no 353, 355, 356, 358.
} 
obispo y cabildo de Burgos sobre la visita, los diezmos, la asistencia a sínodos y otros derechos eclesiásticos. El monasterio cedía en sus pretensiones sobre el nombramiento y destitución de clérigos en sus iglesias (los clérigos debían ser ordenados por los obispos a los que juraban obediencia). En el apartado referente a los diezmos el monasterio mantendría la tercia episcopal en aquellas iglesias de su propiedad que ya eran parroquiales a mediados del siglo XII, abandonándola para las integradas en su patrimonio con posterioridad a esos tiempos y renunciaría al diezmo de todos los collazos y colonos que trabajaran heredades en lugares en que el monasterio no poseía la iglesia parroquial ni percibía la tercia episcopal ${ }^{64}$. Estos sucesivos acuerdos no acabaron con la tensión entre las dos instituciones, a pesar de que la intervención episcopal se expresaba de forma cada vez más intensa y contundente a la hora de regular sobre diezmos, primicias y oblaciones. Actitud por otra parte refrendada por las disposiciones conciliares del IV Concilio de Letrán (1215) que supusieron un gran apoyo al ejercicio pleno de los atributos episcopales ${ }^{65}$. San Salvador de Oña continuaba disponiendo de iglesias monasteriales que estaban desempeñando funciones atribuidas a las parroquias de la diócesis y se resistía a desprenderse de los derechos tradicionalmente ejercidos; de hecho continuaba controlando las rentas parroquiales de sus iglesias. En 1265 cede al clérigo Juan la iglesia de Santa María de Bárcena de Cudón, también en Cantabria, asignándole la mitad de los beneficios parroquiales y estableciendo que la procuración fuese entregada al abad ${ }^{66}$.

\subsection{Otras formas de enfrentamiento por los derechos parroquiales}

Estas disputas jurisdiccionales entre obispos y abades por el control de las entidades parroquiales no solo se manifestaron mediante litigios ante la sede apostólica romana, como hemos tenido ocasión de observar. Parece, como veremos a continuación, que desde el Obispado también se contemplaron otros procedimientos para conseguir la sujeción eclesiástica de todas

\footnotetext{
${ }^{64}$ Respecto a los diezmos y las tercias se establece que todos los colonos o collazos deben pagarlos en las iglesias parroquiales en las que "audiunt divina officia et ecclesiastica percipiunt sacramenta", a no ser en aquellos lugares donde la iglesia era íntegra del monasterio o donde los monjes habían adquirido la tercia del diezmo que el obispo de Burgos debía percibir por derecho común. Además para determinar el estatus de los centros de culto integrados en el patrimonio monástico, el acuerdo recogía la necesidad de efectuar una pesquisa entre tres comisionados de la iglesia de Burgos y tres del monasterio. Ibidem, $\mathrm{n}^{\circ} 515$.

${ }^{65}$ Véase al respecto. Maccarrone 1984, en donde se redefinen las obligaciones de los clérigos parroquiales para con el Obispo. En 1255 el Obispo intermedia entre los clérigos de varios pueblos y el prior de San Pedro de Tejada dependiente de Oña. Oceja 1983, n 161.

${ }^{66}$ Oceja $1983, \mathrm{n}^{\mathrm{o}} 185$.
} 
las instancias religiosas e imponer sus derechos episcopales en las iglesias monasteriales de su diócesis, algunas todavía exoneradas de la intervención de los prelados. Desde finales del siglo XIII el acusado interés episcopal en el encuadramiento parroquial suscitó un gran celo por determinar qué iglesias alcanzaban esa categoría, la de parroquia, donde se debían oyr las oras e dezmar e premençiar e fazer todas aquellas cosas que christianos deven facer a la iglesia do son parrochianos e deven recibir todos los sacramientos de la Eglesia $^{67}$, con objeto de diferenciarlas de aquellas otras iglesias, ermitas, que no podían proporcionar los sacramentos y por tanto disponer de feligreses ${ }^{68}$. Y, sobre todo, se agudiza la pugna sobre quién o quienes tenían derecho a percibir las ofrendas, diezmos y primicias de las iglesias parroquiales. Aquí competían entre sí constantemente los obispados y los monasterios, los clérigos, las comunidades y concejos locales.

Las fuentes informan de litigios entre concejos y monasterios por las iglesias parroquiales. Debe tenerse en cuenta que en este juego de intereses por el control de los recursos de los centros parroquiales locales también comenzaron a manifestarse los concejos, cada vez más fortalecidos, representados muchas veces por los clérigos que servían la iglesia. Isabel Alfonso ha interpretado con sólidos argumentos los enfrentamientos de comunidades campesinas lideradas por sus clérigos contra monasterios como Oña, como una modalidad de lucha campesina para oponerse a las detracciones decimales o para capitalizar en su beneficio los recursos eclesiásticos que ellos mismos producían ${ }^{69}$.

Se puede considerar que las manifestaciones que aparecen mejor documentadas de esta oposición activa de las comunidades campesinas al poder de los monasterios que se beneficiaban de las rentas decimales, fueron básicamente dos. Una fue la de apropiarse de los derechos de iglesias monasteriales que ejercían funciones parroquiales. Y otra, la de abandonar las iglesias parroquiales monasteriales y promover el culto en otras iglesias locales, intentando modificar su categoría con objeto de convertirlas en instituciones parroquiales. En cualquiera de los casos era absolutamente imprescindible contar con la aprobación y licencia del obispo de la diócesis.

En la documentación de Oña existen suficientes muestras de ambas formas de enfrentamiento. San Salvador ya había sufrido usurpaciones de iglesias desde el siglo XII como fue la de Arrigorriaga, donada por los señores de Vizcaya, arrebatada y restituida sucesivamente durante toda la Edad

\footnotetext{
${ }^{67}$ Oceja 1986a, $\mathrm{n}^{\circ} 350$.

${ }^{68}$ Ibidem, ${ }^{\circ} 392$.

${ }^{69}$ Alfonso 2010, p. 31.
} 
Media $^{70}$. Sucesos similares se dieron en otros lugares. En el año 1243 Oña demandó a los clérigos de Nocedo que pretendían hacer suya la iglesia de San Cristóbal, que pertenecía a Oña ${ }^{71}$. Así ocurrió también pocos años después cuando la misma abadía se querellaba contra el concejo de Hornillatorre porque tenía la iglesia forzada e tomaban los derechos della sin razon ${ }^{72}$. O cuando se procedió a la ocupación indebida durante treinta años de la iglesia de San Andrés de Asia, de Oña, por los clérigos apoyados por el propio arcipreste de $\mathrm{Soba}^{73}$. De la misma manera, existen testimonios de clérigos que intentaron, algunas veces con el apoyo del propio concejo del lugar, transformar en parroquiales algunas ermitas con el objetivo de establecer una nueva parroquia, controlar la iglesia y percibir los diezmos y primicias en abierta competencia con los derechos de iglesias parroquiales de monasterios como San Salvador de Oña ${ }^{74}$. Unas veces fueron los concejos o sus representantes los instigadores de la promoción de alguna otra iglesia local; es muy expresivo el caso de los concejos de Berrueza de Espinosa y de Quintanilla, que promovían el culto en ermitas en perjuicio de las parroquiales de Oña, Santa María y San Nicolás ${ }^{75}$. En otras ocasiones eran los clérigos del lugar, como en el caso de Domingo y de García en Matarrepudio y en Villasana de Mena, sin duda con el apoyo tácito de la comunidad, quienes intentaron oficiar en ermitas con el mismo objetivo $^{76}$. En el caso que analizaremos más detenidamente, la iglesia monasterial parroquial de Santa Eulalia de Liencres, se dieron ambas formas: se intentó horra.

${ }^{70}$ Curiel 2009, pp. 258-259. En este caso, Oña denunció la usurpación al obispo de Cala-

${ }^{71}$ Oceja 1983, $\mathrm{n}^{\circ} 139$.

${ }^{72}$ En 1277 el Obispo había comisionado al arcipreste de Montija para que obligase a los hombres de Hornillalatorre a que abandonasen sus pretensiones sobre la titularidad de los derechos de la iglesia del citado lugar en contra de los derechos legítimos de Oña, petición a la que accede el concejo del lugar tras renunciar a la mitad de los derechos y pertenencias de la Iglesia. Oceja 1983, no 213 y 214. Ese mismo día el caballero Pero López también renuncia a la "sesma" parte de la iglesia que le pertenecía, aunque diecisiete años más tarde el clérigo Alfonso Pérez, posiblemente su hijo o nieto, tal y como él mismo afirma, se acusaba de haber cantado la iglesia y de pedir los diezmos con pecado, sin autorización de Oña. Ibidem, $\mathrm{n}^{\mathrm{o}} 215$ y Oceja 1986a, no 416.

${ }^{73}$ Oceja 1983, $\mathrm{n}^{\circ}$ 240, 243, 244, 247.

${ }^{74}$ En estos episodios de enfrentamiento, en los cuales no cabe duda de que entraban en juego muchos intereses, el monasterio de Oña reclamaba siempre sus derechos, y de hecho consiguió, al menos aparentemente, la renuncia, más o menos voluntaria, de algunos de estos clérigos. Este fue el caso del clérigo García que dejó de cantar una iglesia por parroquial y reconoció que dicha categoría pertenecía a la iglesia del monasterio de Oña. Oceja 1986a, nº 378 . En otros casos, como el de Santa Eulalia, como veremos, Oña hubo de recurrir reiteradamente a la justicia para conseguir su recuperación.

${ }^{75}$ Ambos concejos querían promocionar la ermita de Santa Cecilia haciéndola cantar por iglesia difusa. Ibidem, $\mathrm{n}^{\circ}$ 392, 395. Véase al respecto la interesante interpretación de estos actos que proporciona Alfonso 2010, p. 34-35.

${ }^{76}$ Ibidem, n ${ }^{\circ} 350,359,378,416$. 
desvincular la iglesia de su dependencia secular de Oña, y se buscaron argumentos que justificaran la transformación de la categoría de la iglesia; de iglesia monasterial parroquial en iglesia difusa, es decir propia de los clérigos hijos o nietos de los patronos vecinos del lugar ${ }^{77}$.

Como se ha afirmado anteriormente todos estos movimientos, resultaran o no fallidos, tenían que contar con la anuencia del obispo de la diócesis donde estaba enclavada la iglesia correspondiente. En primer lugar porque, como autoridad máxima en esa materia, era quien estaba capacitado para autorizar y legitimar bien a los nuevos propietarios de la iglesia parroquial objeto de disputa o bien reconocer el nuevo estatuto de la iglesia, caso de acceder a transformar una ermita en iglesia parroquial, para lo que se elegía especialmente, con o sin fundamento, el régimen de iglesia difusa. Y en segundo lugar, porque era el Obispo quien reconocía o proveía de clérigos con órdenes a la iglesia en cuestión para poder servir e cumplir todas las oras cumplidamientre. Ello explica el que estas comunidades y sus clérigos tuviesen que acudir al prelado o al arcediano para que les diese carta $^{78}$, es decir para que les proporcionara la licencia y legitimara su acción. De manera que es muy probable que desde las propias sedes episcopales se estimularan o al menos se secundaran tácitamente las iniciativas reivindicativas de concejos o de clérigos de algunos lugares para hacerse con el control de las iglesias parroquiales, porque con ello el Obispado se garantizaba la percepción, siempre solicitada y nada desdeñable, de la tercia canónica. De hecho, cuando los clérigos y el concejo de Torme abandonaron la iglesia monasterial parroquial e intentaron modificar la categoría de una ermita en iglesia difusa afirman que les fizieron entender que podían fazer otra iglesia difusa para sus fios e para los naturales del lugar ${ }^{79}$.

Como contrapartida a este reconocimiento y legitimación del Obispado, las nuevas iglesias parroquiales podían quedar en manos de sus clérigos, los vecinos del lugar entregaban sus diezmos, primicias y ofrendas, y las sedes episcopales conseguían garantizarse las rentas eclesiásticas que les correspondían ${ }^{80}$. Derechos que, como ya se ha indicado, las iglesias monasteriales parroquiales de Oña no satisfacían a pesar de las concordias a las que había llegado desde el siglo XII con los prelados burgaleses por el abono de los diezmos que secundum canones debetur episcopis ${ }^{81}$. No debe olvidarse que con estas

${ }^{77}$ Oceja $1986 \mathrm{c}, \mathrm{n}^{\circ} 617$.

${ }^{78}$ Oceja 1986a, $n^{\circ} 416$.

${ }^{79}$ Pereda 1984, $\mathrm{n}^{\circ} 445$.

${ }^{80}$ Lo que suponía que de los frutos de la iglesia el Obispo percibiese una tercia, los clérigos otra y la restante se dedicara a la fábrica del templo, tal y como era perceptivo en la legislación canónica. López 2002, p. 432. Curiel 2009, pp. 113-136.

${ }^{81}$ Garrido $1983, \mathrm{n}^{\circ} 139$. Véase al respecto el interrogatorio de los comisionados papales a los testigos presentados por Oña sobre la titularidad de los diezmos. Ibidem, n ${ }^{\circ} 107$. 
actuaciones de comunidades, concejos y clérigos se expresaba una oposición al poder de dominios monásticos como Oña, pero no a las estructuras parroquiales; de hecho el concejo controlaba el centro de culto pero acatando la autoridad y cuota episcopal ${ }^{82}$.

Como es obvio, los dominios monásticos como Oña se resistían a perder los derechos de sus iglesias monasteriales parroquiales y como era preceptivo en esos casos desde el siglo XIII acudían al rector de la jerarquía eclesiástica, al señor obispo, para que impartiera justicia y resolviera las desavenencias con los concejos y clérigos en el propio palacio episcopal ${ }^{83}$. De manera que, paradójicamente, el Obispo o sus vicarios debían de intervenir y dirimir en unos juicios en los que el propio Obispado había colaborado con una de las partes implicadas.

Para poder observar esta actitud conjunta entre comunidades, clérigos y obispado frente a las iglesias monasteriales parroquiales tenemos la fortuna de contar con una fuente de excepción en la que se recoge de una manera mucho más explícita que en los casos citados anteriormente, el comportamiento y responsabilidad de cada uno de ellos en estos procesos. Se trata de un complejo y largo enfrentamiento suscitado en el siglo XIV entre unos clérigos y la abadía de Oña por la titularidad y los derechos de la iglesia de Santa Eulalia de Liencres (Cantabria). Oña acusaba a los clérigos de haberse apropiado por la fuerza de la iglesia, dependiente desde el siglo XI de la abadía de San Salvador de Oña (exenta de la autoridad episcopal) y de estar cobrando los diezmos y primicias de sus feligreses. Y los clérigos se defendían afirmando que la iglesia les pertenecía por su carácter de iglesia difusa. El pleito se planteó ante el obispo de Burgos, autoridad competente como juez eclesiástico responsable del juicio en cuanto que el lugar de Liencres estaba en territorio diocesano de la sede burgalesa y se prolongó durante más de dieciséis años.

\subsubsection{El caso de Santa Eulalia de Liencres: el intento de transforma-} ción de una iglesia monasterial parroquial dependiente de San Salvador de Oña en una iglesia parroquial difusa de hijos de villa

Antes de exponer el desarrollo de los acontecimientos concretos acaecidos en el siglo XIV, es preciso conocer algunos antecedentes de la iglesia de Santa Eulalia así como de los contendientes implicados en el conflicto.

${ }^{82}$ Alfonso 2010, p. 33. Aunque es evidente el rechazo y los fraudes generalizados que suscitaba el pago del diezmo. Véase al respecto la carta de Alfonso X de 1255. Pereda 1984, $\mathrm{n}^{\circ} 24$.

${ }^{83}$ Álamo 1950, n 438, 439, 470. Oceja 1983, n 139. 


\subsubsection{La iglesia de Santa Eulalia}

La iglesia, ubicada en Liencres, en territorio diocesano de la jurisdicción de la mitra burgalesa desde su restauración, había sido, probablemente, la iglesia de un antiguo monasterio conocido desde la novena centuria. Desde el siglo XI iglesia y monasterio pasaron a depender de la abadía de San Salvador de Oña y en el siglo XIV se había convertido en iglesia monasterial parroquial de la villa de Liencres ${ }^{84}$. Por esta condición no satisfacía ningún derecho al obispo de Burgos a pesar de estar enclavada dentro de su jurisdicción, pues era Oña la que, por sus exenciones, percibía y retenía los derechos episcopales.

La forma de gestión del monasterio e iglesia de Santa Eulalia desde la abadía de Oña había sido, al menos desde mediados del siglo XIII, época del primer arrendamiento documentado, hasta el momento de la apropiación de los clérigos, mediante la cesión en arriendo a familias significativas oriundas de la zona. Y así se conoce que había sido arrendada y, sobre todo, subarrendada en sucesivas ocasiones. Las obligaciones contraídas por los arrendatarios de Santa Eulalia con la abadía de Oña implicaban siempre una vinculación con el monasterio y consistían en abonar una renta anual, en la provisión del yantar, cuando el abad de Oña acudiese al monasterio de Santa Eulalia, en el pago de la procuración y en la responsabilidad de la atención al culto de la iglesia ${ }^{85}$, ya que eran los propios arrendatarios los que tenían la capacidad de asignar los clérigos en nombre del abad y de la comunidad de Oña ${ }^{86}$. Se sabe que Santa Eulalia, al menos desde comienzos del siglo XIV, ejercía como iglesia con cura de almas y realizaba las funciones de parroquia de la villa de Liencres, con capacidad para atender las necesidades de los feligreses.

Para entender el interés que suscitaba la iglesia en el siglo XIV hay que recordar que en esa época era la institución parroquial de una villa que por los cambios en las pautas del poblamiento bajomedieval y el aumento demográfico aparecía cada vez más populosa (era considerada entonces como un gran pueblo con varios barrios dispersos ${ }^{87}$ ) y próspera, próxima a la pujante ciudad de Santander. Constituía un enclave importante del señorío de la Vega: allí se ubicaba un castillo que había heredado uno de los hijos del almirante Garci Laso de la Vega ${ }^{88}$, y allí se encontraba además alguno de los

\footnotetext{
${ }^{84}$ Puede consultarse al respecto Díez (en prensa).

${ }^{85}$ Según se puede deducir del propio arrendamiento del monasterio de Santa Eulalia en 1262 y de otros contratos similares. Álamo $1950, \mathrm{n}^{\circ} 559$ y 548.

${ }^{86} \mathrm{El}$ derecho de presentación de clérigos. Oceja 1986c, no 601, p. 48. "Ponia y e sacava a quien quería como en cosa suya". Ibidem, p. 50.

${ }^{87}$ Uno de los testigos expresa que "avia allí gran pueblo". Ibidem, p. 80

${ }^{88}$ Pérez 1979, p. 40.
} 
palacios de Diego Gutiérrez de Ceballos, linaje local, muy significativo en las Asturias de Santillana ${ }^{89}$. Características que hacían cada vez más atractivo el control de la iglesia parroquial y la captación de unos beneficios, (diezmos, primicias, ofrendas y otras rentas eclesiásticas), crecientes. No debe olvidarse, como afirma Curiel Yarza, que la parroquia podía constituir un importante centro de recepción de rentas, a veces considerables y, sobre todo, estables ${ }^{90}$. $\mathrm{Y}$ así se entiende que en ese momento fuesen codiciadas, sin duda, por la propia comunidad de Liencres, representada por sus clérigos hijos de villa, por el obispado de Burgos y evidentemente por la abadía de Oña; no hay más que observar el celo y el coraje con el que Oña pleiteó y defendió sus antiguos derechos sobre la iglesia.

\subsubsection{Los protagonistas implicados en el enfrentamiento}

En primer lugar fueron los denominados clérigos de Liencres los que tomaron la iniciativa y desencadenaron el proceso. Pero ¿quiénes eran estos clérigos y porqué se intentaron apropiar de los derechos de la iglesia de Santa Eulalia y se enfrentaron con el monasterio de Oña? El análisis sobre la procedencia y personalidad de los clérigos revela que en ellos concurrían dos circunstancias muy significativas; eran los que en ese momento, comienzos del siglo XIV, aparecían, con diferentes categorías, como los responsables del culto de la iglesia parroquial de Santa Eulalia. Y además se ha podido comprobar que eran hijos o nietos, herederos o parientes directos de las ramas familiares que habían poseído algún tipo de derechos en la iglesia de Santa Eulalia como arrendatarias o subarrendatarias de Oña. Ambas características dotaron, sin duda, de una cierta "justificación" al movimiento de rebeldía liderado por ellos, al intento de apropiación de la titularidad y derechos de la iglesia de Santa Eulalia frente a la abadía de Oña.

Los argumentos esgrimidos por los clérigos se basaban en la afirmación de que la iglesia era suya. No se descarta que la confusión generada respecto a la titularidad de la iglesia en ese momento por su larga y compleja trayectoria de arrendamientos y subarrendamientos sucesivos hubiera facilitado esa creencia. La iglesia de Santa Eulalia, al menos desde la segunda mitad del siglo XIII, había sido objeto de sucesivos arrendamientos por parte del monasterio de San Salvador de Oña a miembros de alguna de las familias más

\footnotetext{
${ }^{89}$ El linaje de los Ceballos poseía en el siglo XIV el patronato de diecisiete iglesias y gozaba de la behetría en cincuenta y cinco lugares en la Merindad de las Asturias de Santillana. González 2010, pp. 55-59.

${ }^{90}$ Véase al respecto Curiel 2009, p. 113.
} 
significativas de la villa. Y, sobre todo, había sido objeto de varios subarrendamientos; el hecho de que uno de los arrendatarios, por haber incurrido en un crimen se hubiese visto obligado a ceder a otra familia de Liencres la mitad de la iglesia y de sus rentas y a subarrendar la otra parte a otros parientes cuando fue obligado a abandonar la villa de Liencres y a marcharse a vivir a otro lugar en pena por el delito cometido, además de provocar constantes enfrentamientos entre las familias beneficiarias, pudo propiciar una cierta confusión respecto a la gestión de los bienes y derechos de la iglesia. Además el hecho de que la cesión en arriendo por parte de Oña de la iglesia de Santa Eulalia desde la segunda mitad del siglo XIII hasta comienzos del siglo XIV hubiera recaído en miembros de unas mismas familias locales y que, a su vez, estos grupos familiares pudieran elegir, como así lo hicieron, para el servicio de la iglesia a sus propios descendientes o parientes fue afirmando la precedencia de los naturales de la villa frente a los foráneos para ocupar los cargos eclesiásticos. Estas circunstancias debieron favorecer la pretensión de los clérigos de Liencres de intentar considerar que la iglesia era de ellos y que debía ser llevada o cantada por los clérigos hijos de parroquianos ${ }^{91}$, naturales de la vi$1 \mathrm{a}^{92}$. Es decir poseída y servida por clérigos hijos de vecinos, que eran los que por tanto debían recaudar y beneficiarse de las rentas de la iglesia, una de las características propias de las iglesias difusas.

Todas estas pretensiones evidentemente se desarrollaron en el contexto de esa lucha de las comunidades campesinas por instrumentalizar a su favor los recursos eclesiásticos. En ese sentido se debe interpretar el que los clérigos, como en otros casos analizados con anterioridad, con la anuencia o al menos la tolerancia de la comunidad de Liencres por los propios beneficios que podía reportarle, (la posibilidad a los hijos de los parroquianos de poder llegar a cantar en la iglesia y participar en sus beneficios ${ }^{93}$ ) intentasen afirmar el carácter difuso de la iglesia de Santa Eulalia, hacerse con sus derechos parroquiales y sustraerse a la punción constante de la abadía de Oña. En su defensa a la hora de reclamar el régimen difuso de la iglesia exponían distintos argumentos; que habían encontrado cartas en las que aparecía como difusa ${ }^{94}$, iglesia difusa de herederos; que había tenido ese carácter desde la época del primer arrendamiento documentado ${ }^{95}$, que la llevaban por suya

\footnotetext{
${ }^{91}$ Oceja $1986 \mathrm{c}, \mathrm{n}^{\circ} 601, \mathrm{p} .78$.

${ }^{92}$ Ibidem, pp. 50 y 53.

${ }^{93}$ Ibidem, pp. 94 y 100.

${ }^{94}$ Ibidem, pp. 56-57.

${ }^{95}$ De hecho el carácter de difusa se dice que lo tenía desde la época de don Rodrigo, primer arrendatario conocido. Un testigo dice que Don Rodrigo tenía la iglesia de Liencres por difusa, San Fructuoso de Miengo por renta y San Andrés por ermita. Ibidem, pp. 101-102.
} 
propia ${ }^{96}$; que después la perdieron y que por eso la entraron de nuevo ${ }^{97}$, etc. Pero está claro que estas afirmaciones no se podían llevar adelante sin legitimación, es decir sin conseguir el respaldo institucional que reconociese y legalizara el nuevo carácter de la iglesia que pretendían. Y por ello debe tenerse en cuenta que los clérigos no actuaban solos en estos episodios de enfrentamiento a Oña; tuvieron que recurrir, como veremos más adelante, al obispo de Burgos para que les proporcionara su correspondiente autorización y licencias. De ahí que los clérigos y sus testigos en el pleito afirmasen una y otra vez que la iglesia la habían ganado del obispo de Burgos: dizian que ge la diera el obispo de Burgos ${ }^{98}$; que la tenían foreada en Burgos ${ }^{99}$. Y que ellos mismos se autotitulasen clérigos de Liencres porque como tales habían sido ordenados por el prelado burgalés.

El abad y la comunidad del monasterio castellano de San Salvador de Oña fue el otro contendiente en este conflicto por la iglesia de Santa Eulalia que Oña defendía de su propiedad desde el siglo XI. ¿Cuáles eran las condiciones del monasterio de Oña en esa época? Y ¿cómo reaccionó ante la apropiación de la iglesia? El episodio protagonizado por los clérigos de Liencres no fue, como hemos tenido ocasión de observar, ni único ni diferente a otros enfrentamientos de los que había sido objeto la abadía castellana desde finales del siglo XIII. Las diferencias respecto a los otros casos conocidos fueron la resistencia que ofrecieron los clérigos y el empeño de Oña en conseguir la recuperación de sus derechos vulnerados y ello a pesar de que la situación que estaba viviendo el monasterio de San Salvador desde finales del siglo XIII, era aparentemente difícil. De hecho aparecía amenazado desde distintas instancias; por la pérdida del papel hegemónico que hasta entonces había desempeñado; por la competencia con el señorío laico representado por la fuerza del linaje emergente de los Velasco, y en tierras de Cantabria por el señorío de la Vega ${ }^{100}$, (recuérdese al respecto que varios vasallos de Oña en Cantabria abandonaron en 1315 su sujeción para hacerse vasallos de Garcilaso de la Vega y de su hijo) ${ }^{101}$; por las reiteradas querellas con el obispado

\footnotetext{
${ }^{96}$ Expresión que destaca su carácter patrimonial en el sentido sugerido por J. Peñalva, como lugar donde vivieron y están enterrados los antepasados, Peñalva 2008, p. 352.

${ }^{97}$ Oceja $1986 \mathrm{c}, \mathrm{n}^{\mathrm{O}} 601$, p. 67.

${ }^{98}$ Ibidem, pp. 52-53.

${ }^{99}$ Ibidem, p. 71.

${ }^{100}$ La figura central de este linaje en este periodo del conflicto fue Garci Laso de la Vega I, "merino mayor por el rey en Castilla e mayormomo mayor del enfant donna María", Oceja $1986 \mathrm{~b}, \mathrm{n}^{\circ} 574$.

${ }^{101}$ Ibidem, n ${ }^{\circ}$ 550. Véase al respecto Pérez 1979, pp. 37-40. Que este linaje contribuyó a disminuir el poder del monasterio de Oña se pone de manifiesto cuando en las cuentas de 1338 se dice en varias ocasiones que Garci Laso de la Vega, en este caso el II, y otros miembros del
} 
de Burgos ${ }^{102}$; por el nuevo protagonismo del núcleo urbano de Frías, etc. Son conocidos los enfrentamientos de Oña con la villa de Frías ${ }^{103}$, con San Millán de la Cogolla ${ }^{104}$, con otros señores territoriales y con comunidades rurales, como se ha visto, con concejos y clérigos deseosos de gestionar sus iglesias parroquiales. Todo ello a pesar del apoyo, al menos nominal, de la monarquía castellana, impelida a confirmar una y otra vez los antiguos privilegios del gran monasterio castellano. No obstante, esta situación no impidió, como afirman Fernando Suárez Bilbao y Gonzalo Viñuales Ferreiro, que el monasterio castellano tuviera todavía una alta capacidad de reacción a la hora de defender sus intereses. De hecho su tesón y fortaleza tuvieron su recompensa cuando logró en ese contencioso el reconocimiento institucional de sus antiguos derechos sobre la iglesia de Santa Eulalia y no fue el único caso. La continua preocupación por el control de su patrimonio y de sus derechos se manifiesta en el desarrollo de una importante actividad judicial: según el libro de Cuentas del año 1338, Oña se gastó casi 9.000 maravedíes en pleitos y procuraciones ${ }^{105}$.

Ya se ha indicado que los clérigos en su oposición a Oña no actuaron solos. No fueron los únicos interesados en arrebatar los derechos de la iglesia monasterial parroquial de Santa Eulalia a la comunidad de Oña. El obispado de Burgos en esa lucha constante por acabar con las prerrogativas de dominios monásticos como Oña, en ese permanente interés en controlar las parroquias de su diócesis, se implicó en este conflicto de dos formas distintas. Una, derivada de que ambos contendientes, los clérigos de Liencres y la abadía de Oña, estaban obligados institucionalmente a acudir, como así lo hicieron en primera instancia, al arbitrio del obispo de Burgos para que, como autoridad suprema, determinase la titularidad de los derechos de la iglesia de Santa Eulalia de Liencres. Pero también es posible deducir otra forma de implicación más sutil del Obispado burgalés en este tipo de conflictos entre comunidades locales y dominios monásticos, muy explícita en el caso de la iglesia de Santa Eulalia. El Obispado, como tradicional competidor con el monasterio de Oña por controlar las iglesias parroquiales de su diócesis y ejercer la plenitud de sus derechos, una vez agotadas las vías convencionales; pleitos, pactos, concordias,

linaje, les "tomaban las rentas por fuerza", como en la Honor de Miengo. Oceja 1986c, n 661 , pp. 251,252 y 253 .

${ }^{102}$ Oceja 1986b, n⿳ 557 . Todavía en 1319 el monasterio de Oña continuaba pleiteando con el obispo de Burgos y consigue sentencia favorable ante la Sagrada Rota de Roma para que el Obispo no le impusiera nuevas exacciones además de la visita y de la procuración.

${ }^{103}$ Véanse al respecto documentos, Oceja 1983, n 195, 219, 228, 229, 230, 231, 233.

${ }^{104}$ Ibidem, $\mathrm{n}^{\circ} 171,172$ a 182.

${ }^{105}$ Suárez, Viñuales 2011. Estos autores sintetizan los enfrentamientos de Oña con distintas instituciones en esa época. 
etc. ante la Santa Sede, que tomaba a veces decisiones arbitrarias, consideró que otra manera de conseguir sus objetivos podía ser promover o secundar desde el propio Obispado la actitud reivindicativa de clérigos y comunidades por el control y gestión de sus parroquias. Debe tenerse en cuenta que con este apoyo conseguía al fin ejercer las atribuciones episcopales y participar en el aprovechamiento de la parte que le correspondía de las rentas de la iglesia. Para ello era necesario dotar de legitimidad a estos traspasos de titularidad y ahí entraba en juego el Obispado y la categoría de iglesia difusa. Categoría que ya se conocía como iglesia comunitaria pero que va a tener un notable papel en estos intentos de sustraer a los dominios monásticos las iglesias monasteriales parroquiales. Con lo que de alguna manera se pone en evidencia que en este conflicto, el Obispo actuó como mediador y juez en la contienda entre los clérigos-comunidad de Liencres y el monasterio de Oña y, a su vez, como parte implicada e involucrada en el enfrentamiento en función de su tácito apoyo a los clérigos "rebeldes". La responsabilidad del obispo y sus vicarios en estos movimientos y en concreto en el de Liencres se manifiesta al comprobar el reconocimiento del que fue objeto la iglesia de Santa Eulalia como parroquial difusa y en el ordenamiento de los clérigos a título específico de Santa Eulalia ${ }^{106}$.

Para mostrar el grado de implicación en el conflicto del propio Obispado debe tenerse en cuanta que uno de los procuradores de los clérigos fue Pero González, canónigo de Cervatos, colegiata integrada en la iglesia catedral, quien defendía que la iglesia sita in burgensi diocesis fue siempre parroquial y difusa in predicta diocesi constitute, spectat e pertinet in temporalibus ad clericos filios patronorum vicinorum istius $l o c i^{107}$. De hecho en la sentencia final, entre las medidas tomadas por el capiscol de Santander también se establece que los vicarios, arciprestes y curas del obispado de Burgos tenían que satisfacer bajo pena de excomunión, las mismas pagas a Oña que los clérigos culpables, lo que pone en evidencia los beneficios que la "rebelión" de los clérigos había estado reportando durante años al obispado de Burgos ${ }^{108}$.

\subsubsection{La reconstrucción de los hechos y el desenlace final}

Conocida la identidad y participación de las partes implicadas en el conflicto resta ahora proceder a la reconstrucción de los hechos acaecidos. Los

${ }^{106}$ Se afirma que el obispo don Gonzalo había ordenado a cuatro clérigos recientemente. Oceja $1986 \mathrm{c}, \mathrm{n}^{\circ} 601$, p. 78.

${ }^{107}$ Ibidem, n ${ }^{\circ} 617$, p. 178.

${ }^{108}$ Ibidem, $\mathrm{n}^{\mathrm{0}} 622$. 
clérigos que atendían la iglesia a comienzos del siglo XIV, en un periodo especialmente conflictivo por la intensa competitividad señorial local ${ }^{109}$, intentaron arrendar la iglesia y sus derechos a Oña directamente ${ }^{110} \mathrm{y}$ ante la negativa del abad a cualquier tipo de negociación procedieron al entramiento por la fuerza. Decidieron, tal y como había ocurrido en otros lugares, desvincular la iglesia de sus compromisos con la abadía de Oña y quedarse con los derechos de la iglesia. Como estos clérigos no tenían aparentemente más derechos sobre la iglesia de Santa Eulalia que los derivados de las relaciones de arrendamiento mantenidas por sus familias con Oña, y la de que, en ese momento, eran los responsables de los servicios de la iglesia, para justificar y defender su "usurpación" tenían que recurrir a algún procedimiento o a alguna instancia que proporcionara legitimidad a su acción. Y como se ha indicado, uno de los medios utilizados era intentar modificar el régimen de la iglesia monasterial. Para ello era preciso primero encontrar una categoría de iglesia reconocida en el Obispado que se ajustara a sus objetivos: la iglesia difusa y, en segundo lugar contar con la aprobación del arcipreste y, sobre todo, la del señor obispo de Burgos $^{111}$. Y con ese objetivo se desarrollaron los contactos entre los clérigos que atendían la iglesia de Liencres y la Sede episcopal para primero intentar modificar el estatus tradicional de patronato monástico de la iglesia de Santa Eulalia; de iglesia monasterial dependiente de Oña, en parroquial difusa sujeta al Obispado burgalés. Y después, para ser presentados al Obispo, conseguir su ordenamiento $^{112} \mathrm{y}$ recibir así legitimidad a sus peticiones para poder reclamar y percibir los derechos de la iglesia.

${ }^{109}$ Cuando Diego Gutiérrez de Ceballos "no estaba en la tierra" (sin saber con precisión los motivos de esta ausencia). Es decir aprovechando posiblemente los conflictos e intereses locales derivados de una coyuntura especialmente compleja. Baste recordar el enfrentamiento entre el linaje de los Ceballos y los señores de la Vega, entre Diego Gutiérrez de Ceballos y Garci Laso de la Vega, con la pérdida temporal de la tierra para Diego Gutiérrez de Ceballos, valedor de Oña. "Dia Gutierre e Garcia Laso de la Vega ovieron la pelea, dia gutierre perdió la tierra", Oceja 1986c, n ${ }^{\circ} 601$, pp. 54,59. O cuando Diego Gutiérrez de Ceballos estuvo ejerciendo como almirante de Castilla, cargo que desempeñó durante tres años. Circunstancias todas ellas especialmente favorecedoras para alcanzar un estado tal que permitiera la apropiación por parte de los clérigos.

${ }^{110}$ Ofrecieron al abad una cantidad (doscientos maravedíes) por renta, suma superior a la que estaba pagando el último arrendatario. Oceja 1986c, nº 601, p. 136.

${ }^{111}$ Cuando un clérigo arrepentido renuncia a cantar la iglesia de un monasterio de Oña como parroquial, es decir percibiendo las primicias y el diezmo, expresa que no lo volverá a hacer "nin por carta que ganase nin oviesa ganada de obispo nin de arçidiano nin de otra persona ninguna". Oceja 1986a, $\mathrm{n}^{\circ}$ 416. Lo que puede indicar que la forma de legitimar los derechos de los clérigos sobre alguna iglesia estaba vinculada al reconocimiento por carta del obispo o del arcediano.

${ }^{112}$ Los clérigos "se ordenaban a titulo de la iglesia de Liencres e por el obispo de Burgos. El arcipreste de Pagazanes les dio la carta para el Obispo". Oceja 1986c, n 601, pp. 81, 94, 95 y 104. 
El prelado de Burgos, tal y como había ocurrido en otras ocasiones y escenarios, debió ver en esta iniciativa tomada por los clérigos una oportunidad para reducir las iglesias monasteriales parroquiales y establecer sus derechos episcopales. Y mediante la correspondiente carta o licencia legitimó la actitud de los clérigos afirmando y acreditando el carácter difuso de la iglesia ${ }^{113}$. Para entender esta acción hay que recordar que la iglesia de Santa Eulalia, al estar bajo la sujeción de la comunidad de Oña, exenta de jurisdicción episcopal, no reconocía ningún derecho al obispo de Burgos, a excepción de la visita y la procuración ${ }^{114}$, a pesar de que la iglesia estaba desempeñando las funciones propias de una iglesia monasterial parroquial. Con el reconocimiento del carácter difuso de la iglesia de Santa Eulalia se atendía la iglesia y mejoraba el control de los feligreses, facultaba a los clérigos hijos de vecinos de la villa a aprovecharse directamente de los beneficios de su iglesia parroquial ${ }^{115}$ y la iglesia quedaba sujeta al Obispado y proporcionaba al Obispo la posibilidad de exigir los derechos episcopales; la obediencia de los clérigos que la regían y la recepción regular de todos sus derechos eclesiásticos: la parte correspondiente de sus diezmos y demás prestaciones como en otras iglesias de su Sede ${ }^{116}$. Rentas que hasta ese momento habían sido detraídas por el monasterio de Oña ${ }^{117}$. Muchos testigos del pleito recordaban en sus relatos al hombre del Obispo recaudar los tercios en la propia iglesia ${ }^{118}$. Estos acontecimientos ponen de manifiesto que efectivamente al prelado burgalés le interesaba apoyar o al menos favorecer la iniciativa de los clérigos en tanto que suponía un paso más en la implantación real y efectiva del ius episcopalis, de su poder, en iglesias monasteriales en territorio de su diócesis.

\footnotetext{
${ }^{113}$ Mediante la necesaria licencia o carta, tal y como afirman los testigos. Ibidem, pp. 52-53 y 71. Uno de los testigos del pleito dice que observó que cuando el Obispo acudió a Santander se vio con los clérigos de Liencres. Ibidem, p. 55.

${ }^{114}$ Así lo afirman reiteradamente los arrendatarios legítimos de Oña: Pero González y su hijo Juan. Ibidem, p. 136.

${ }^{115}$ A partir de ese momento eran los clérigos los que recogían y retenían las rentas y derechos de la iglesia de Santa Eulalia y se lo repartían por cabezas. Oceja 1986c, nº 601, p. 107.

${ }^{116}$ Un maravedí de la buena moneda al año equivalente a "seys maravedís desta moneda". Ibidem, p. 105. Esta cantidad se consideraba "un gran derecho". Ibidem, pp. 83-84. Derechos que recogía el hombre del Obispo. Ibidem, p. 84. Otros varios testigos se refieren también al tercio episcopal. Ibidem, pp. 88-89 y 91. Parece que uno de los hombres del Obispo fue Gonzalo Roiz de Escalante. Ibidem, pp. 91-92. Y otro García Sánchez de Arce que tenía arrendados los tercios del Obispo y los recaudaba el hijo de Gonzalo Miguélez por él. Ibidem, p. 97.

${ }^{117}$ El monasterio de Oña tradicionalmente cobraba los "diezmos de pan e de crianza e de labranza". Ibidem, p. 58.

${ }^{118}$ Ibidem, p. 57. El Obispo tenía arrendados los tercios a Gonzalo Roiz de Escalante que los cogía por él. Ibidem, p. 59.
} 
Ante esta actitud conjunta de clérigos-Obispado, la comunidad de Oña reaccionó e inició el pleito en 1313, como en otras ocasiones ante la autoridad competente como juez eclesiástico: el obispo de Burgos ${ }^{119}$. El vicario general del obispo burgalés dictó sentencia a favor de Oña, sentencia que no debió cumplirse porque al año siguiente hubo de ser ratificada por el auditor de la Sagrada Rota de Roma ${ }^{120}$. El desenlace final de la querella fue la resolución favorable al monasterio de Oña al que se reconoció la titularidad sobre la iglesia de Santa Eulalia de Liencres y la recuperación del estatuto de iglesia monasterial parroquial sujeta a Oña. Y ello supuso la penalización a los clérigos y a los funcionarios del Obispado por esa usurpación continuada. Finalmente, en 1329 se ponía en disposición del monasterio de Oña, la susodicha iglesia $^{121}$. Esta recuperación de la iglesia de Santa Eulalia a Oña resultó efectiva pues en las cuentas del año 1338, en concreto en el inventario de las rentas en dinero que recibía la abadía castellana, se incluyen las procedentes de Santa Eulalia de Liencres ${ }^{122}$.

A pesar de que en los referentes citados sobre concejos o clérigos "rebeldes" enfrentados a Oña casi siempre se acababa reconociendo y restableciendo los derechos de la abadía castellana ${ }^{123}$, tal y como ocurrió con Santa Eulalia, aunque para ello se hubiera de recurrir en algunos casos al tribunal de la Santa Sede, ¿hasta qué punto esa fue la norma habitual? O ¿es que únicamente se registraron en la documentación de Oña los casos resueltos a su favor? De no haber sido así, no se entendería el que el obispado de Burgos continuara incrementando, a finales de la Edad Media, el control sobre iglesias monasteriales parroquiales.

\footnotetext{
${ }^{119}$ En las actas del pleito planteado ante el obispo de Burgos se dice que los clérigos entraron sin razón y sin derecho y les quitaron (a Oña) la posesión, las rentas y los derechos de la iglesia de Santa Eulalia. Oceja 1986b, $n^{\circ} 540$. En el texto de 1323 se recuerda el acontecimiento. Oceja $1986 \mathrm{c}, \mathrm{n}^{\circ} 601$, p. 124.

${ }^{120}$ Ibidem, n $\mathrm{n}^{\circ} 617,619$.

${ }^{121}$ Ibidem, $\mathrm{n}^{\circ} 622$.

${ }^{122}$ Ibidem, $\mathrm{n}^{\circ}$ 661. En ese momento la iglesia rendía 350 maravedíes. También estaban integradas en Oña las iglesias de Santa María de Berrueza que rentaba 80 maravedíes y la de San Nicolás de Espinosa que ascendía a 500 maravedíes, a pesar de los intentos de los respectivos concejos de esos lugares por relegar a estas iglesias con funciones parroquiales y convertir la ermita de Santa Cecilia en parroquial. Véase al respecto Oceja 1986a, nº 392 y 395.

${ }^{123}$ Aunque en algún caso concreto parece que no, como por ejemplo, en el litigio entre los clérigos y concejo de Sotovellanos con la abadía de Oña por la iglesia de San Pantaleón que aquellos reclamaban suya como difusa desde antiguo, allí se acordó ante el obispo de Burgos permitir que se celebrase culto en ella y que se pudieran recolectar también los diezmos y primicias. Álamo $1950, n^{\circ} 439$.
} 


\section{CONCLUSIONES}

El largo y tortuoso proceso desencadenado entre el obispado de Burgos y el monasterio de San Salvador de Oña por definir sus respectivos territorios y recursos: derechos parroquiales, control de los diezmos y servicio de los fieles, constituye una demostración de que frente a las tesis tradicionales que venían a proponer una geografía eclesiástica basada en la lejana configuración administrativa del Imperio romano, esta investigación avala la idea sostenida con firmeza por Florian Mazel y los demás autores de la obra L'espace du diocèse de que la construcción de las diócesis fue una historia medieval llena de avatares y de prolijos y lentos movimientos por parte de muchos interesados e implicados. La ejemplificación de alguno de esos movimientos, especialmente el de la iglesia de Santa Eulalia de Liencres, ofrece una imagen más reveladora de la complejidad del proceso y sobre todo del protagonismo de los diferentes actores que intervinieron.

\section{BIBLIOGRAFÍA CITADA}

Abajo Martín, Teresa (1986), Documentación de la catedral de Palencia (1039-1247), Palencia, Ediciones J.M. Garrido Garrido.

Álamo, Juan del (1950), Colección diplomática de San Salvador de Oña (8221248), Madrid, Consejo Superior de Investigaciones Científicas. Escuela de Estudios Medievales (Textos; 12).

Alfonso, Isabel (2010), Iglesias rurales en el norte de Castilla: Una dimensión religiosa de las luchas campesinas durante la Edad Media, en Garrabou Segura, Ramón; Robledo Hernández, Ricardo (eds.), Sombras del progreso: las huellas de la Historia Agraria, Barcelona, Crítica, pp. 27-65.

Álvarez Palenzuela, Vicente Ángel (2004), Jurisdicción episcopal y monástica. Su delimitación entre el obispado de León y el monasterio de Sahagún, en Domínguez García, Manuela; Díaz y Díaz, Manuel Cecilio; Díaz de Bustamante, Mercedes (coords.), Estudios dedicados a José María Fernández Catón, León, Centro de Estudios e Investigación "San Isidoro", pp. 65-85.

Calleja Puerta, Miguel (2000), La formación de la red parroquial de la diócesis de Oviedo en la Edad Media, Oviedo, Real Instituto de Estudios Asturianos.

Curiel Yarza, Josu (2009), La parroquia en el país vasco-cántabro durante la Baja Edad Media c.1350-1530. Organización eclesiástica, poder señorial territorio y sociedad, Bilbao, Universidad del País Vasco. 
Díez Herrera, Carmen (en prensa), El monasterio e iglesia de Santa Eulalia de Liencres (Cantabria) en la Edad Media.

Faci Lacasta, Francisco Javier (1977), Sancho III el mayor de Navarra y el monasterio de San Salvador de Oña, "Hispania" 37/136, pp. 299-317.

Flórez, Henrique (1737), España Sagrada. Theatro Geographico-historico de la iglesia de España. Tomo XVI de la Santa Iglesia de Astorga, Madrid.

García y García, Antonio (ed.) (1997), Synodicon Hispanum. VII: Burgos y Palencia, Madrid, Biblioteca de Autores Cristianos.

Garrido Garrido, José Manuel (1983a), Documentación de la catedral de Burgos (804-1183), Burgos, Ediciones J.M. Garrido Garrido.

Garrido Garrido, José Manuel (1983b), Documentación de la catedral de Burgos (1184-1222), Burgos, Ediciones J.M. Garrido Garrido.

González de Riancho Colongues, Aurelio (2010), El linaje de los Ceballos. Orígenes norteños y memoria medieval, Santander, Grupo publicitario Cruzial.

Lop Otín, María José (2009), Los estudios sobre la vida parroquial castellana. Una aproximación desde la Edad Media, en Valdivielso, María Isabel; Martínez Sopena, Pascual (dirs.), Castilla y el mundo feudal. Homenaje al Profesor Julio Valdeón, Valladolid, Junta de Castilla y León - Universidad de Valladolid, vol. 3, pp. 525-540.

López Alsina, Fernando (2002), El encuadramiento eclesiástico como espacio de poder de la parroquia al obispado, en Los espacios de poder en la España medieval.XII Semana de Estudios Medievales. Nájera 2001, Logroño, Instituto de Estudios Riojanos, pp. 425-457.

Maccarrone, Michele (1984), Cura animarum e parochalis sacerdos nelle constituzioni del IV Concilio lateranense (1215): applicazioni in Italia nel sec. XIII, en Pievi e parrocchie in Italia nel Basso Medioevo (sec.XIII-XV). Atti del VI convegno di storia della Chiesa in Italia (Firenze 21-25 sett. 1981), Roma, Herder, pp. 81-195.

Mazel, Florian (dir.) (2008), L'espace du diocèse. Genèse d'un territoire dans l'Occident médiéval (Ve-XIIIe siècle), Rennes, Presses Universitaires de Rennes.

Martínez Díez, Gonzalo (1982), Fueros locales en el territorio de la provincia de Burgos. Burgos, Caja de Ahorros Municipal de Burgos.

Martínez Sopena, Pascual (2002), Espacio y sociedad en Palencia durante los siglos XI y XII, en Enciclopedia del Románico en Castilla y León (I), Aguilar de Campoo, Fundación Santa María la Real. Centro de Estudios del Románico.

Martínez Sopena, Pascual (2007), Señores laicos y comunidades campesinas en León hacia el año 1100, en Del Ser Quijano, Gregorio; Martín 
Viso, Iñaki (eds.), Espacios de poder y formas sociales en la Edad Media: estudios dedicados a Ángel Barrios, Salamanca, Universidad de Salamanca.

Oceja Gonzalo, Isabel (1983), Documentación del monasterio de San Salvador de Oña (1032-1284), Burgos, Ediciones J.M. Garrido Garrido.

Oceja Gonzalo, Isabel (1986a), Documentación del monasterio de San Salvador de Oña (1285-1310), Burgos, Ediciones J.M. Garrido Garrido.

Oceja Gonzalo, Isabel (1986b), Documentación del monasterio de San Salvador de Oña (1311-1318). Indices (1032-1318), Burgos, Ediciones J.M. Garrido Garrido.

Oceja Gonzalo, Isabel (1986c), Documentación del monasterio de San Salvador de Oña (1319-1350), Burgos, Ediciones J.M. Garrido Garrido.

Olmedo Bernal, Santiago (1987), Una abadía castellana en el siglo XI. San Salvador de Oña (1011-1109), Madrid, Universidad Autónoma.

Peña Bocos, Esther; Álvarez LLopis, Elisa (2000), La génesis de la organización eclesiástica en el territorio regional, en Maruri Villanueva, Ramón (ed.), La iglesia en Cantabria, Santander, Obispado de Santander, pp. 109-136.

Peñalva Gil, Jesús (2008), Las iglesias patrimoniales en la Castilla medieval. La iglesia parroquial de San Nicolás de Burgos: Institución, ordenanzas y regla de 1408, "Anuario de Estudios Medievales" 38/1, pp. 301-366.

Pereda Llarena, Francisco Javier (1984), Documentación de la catedral de Burgos (1294-1316), Burgos, Ediciones J.M. Garrido Garrido.

Pereda Llarena, Francisco Javier (1986), Aproximación al estudio del señorío eclesiástico y de la capitación decimal de la sede episcopal burgalesa (Siglos XI-XIII), Universidad de Valladolid (memoria de licenciatura inédita).

Pérez Bustamante, Rogelio (1979), Sociedad, Economía Fiscalidad y Gobierno en las Asturias de Santillana (S. XIII-XV), Santander, Librería Estudio.

Ruiz Asencio, José Manuel (1987), Colección documental del Archivo de la catedral de León, León, Centro de Estudios e Investigación "San Isidoro", vol. 4.

Serrano, Luciano (1935-1936), El Obispado de Burgos y Castilla primitiva. Siglos V-XIII, 3 vols., Madrid, Instituto Valencia de Don Juan.

Suárez Bilbao, Fernando; Viñuales Ferreiro, Gonzalo (2011), El monasterio de San Salvador de Oña en la Baja Edad Media, "Circunstancia: revista de ciencias sociales del Instituto Universitario de Investigación Ortega y Gasset" 24, s/p. (Ejemplar dedicado a Mil años de historia: el monasterio de San Salvador de Oña). 
Villacorta Rodríguez, Tomás (2004), Conflictos entre el obispo de León y el abad del monasterio de Sahagún, en Domínguez García, Manuela; Díaz y Díaz, Manuel Cecilio; Díaz de Bustamante, Mercedes (coords.), Escritos dedicados a José María Fernández Catón, León, Centro de Estudios e Investigación "San Isidoro", pp. 1445-1496.

Fecha de recepción del artículo: noviembre 2012

Fecha de aceptación y versión final: marzo 2014 